\title{
Molecular differentiation of Turkey cattle isolates of Fasciola hepatica and Fasciola gigantica
}

\author{
S. $\operatorname{SIMSEK}^{1 *}$, A. E. UTUK ${ }^{2}$ I. BALKAYA ${ }^{3}$
}

\begin{abstract}
${ }^{1}$ Department of Parasitology, Faculty of Veterinary Medicine, University of Firat, 23119, Elazig-Turkey, E-mail: ssimsek@firat.edu.tr; ${ }^{2}$ Central Veterinary Control and Research Institute, Parasitology and Bee Diseases Laboratory, 06020, Etlik, Ankara-Turkey; ${ }^{3}$ Department of Parasitology, Faculty of Veterinary Medicine, University of Ataturk, Erzurum-Turkey
\end{abstract}

\begin{abstract}
Summary
The most common and widespread liver flukes of the genus Fasciola are Fasciola hepatica and F. gigantica. Adults of both species occur in many domestic ruminants and in humans and can cause serious disease. The differential diagnosis of these flukes infection is very important because of their different transmission and epidemiological characteristics. A simple and rapid PCR-restriction fragment length polymorphism (RFLP) assay, using the common restriction enzymes AluI and RsaI, is described to distinguish between both fasciolid species. After the digestion of the mitochondrial cytochrome c oxidase 1 (CO1) PCR product with the restriction enzyme AluI, the RFLP profile obtained from $F$. hepatica revealed two fragments, whereas $F$. gigantica was not cut. The RsaI digestion generated two fragments from $F$. gigantica, whereas it did not cut the PCR product from $F$. hepatica. Results were confirmed with $\mathrm{CO} 1$ sequence analysis of both $F$. hepatica and $F$. gigantica. The present study suggests that the PCRRFLP method described here can be used for the proper identification of Fasciola species.
\end{abstract}

Keywords: Fasciola hepatica; Fasciola gigantica; PCRRFLP; cattle; Turkey

\section{Introduction}

Fasciolosis is an economically important disease of domestic livestock, in particular cattle and sheep, and occasionally man. The disease is caused by digenean trematodes of the genus Fasciola, commonly referred to as liver flukes. The two species most commonly implicated as the aetiological agents of fasciolosis are $F$. hepatica and $F$. gigantica (family Fasciolidae). F. hepatica has a worldwide distribution but predominates in temperate zones while $F$. gigantica is found on most continents, primarily in tropical regions (Andrews, 1999). Adlard et al. (1993), using the second internal transcribed spacer, demonstrated that the identity between $F$. hepatica and $F$. gigantica was $97.2 \%$ and that between $F$. hepatica and Fascioloides magna was $86.8 \%$. They were also able to show that the Fasciola species from Japan was almost identical to $F$. gigantica. This work was confirmed by Hashimoto et al. (1997) who used the second internal transcribed spacer and mitochondrial cytochrome $c$ oxidase subunit 1 (CO1) sequences to show that the Japanese Fasciola species was a strain of $F$. gigantica. Molecular biology techniques have enabled the identification of, and in particular the discrimination between, parasite species which are so closely related as to be difficult to distinguish by morphological methods (McManus \& Bowles, 1996). These trematode species are involved in both animal and human. The geographical overlapping gives rise to many problems in the diagnosis. Traditional methods of identification of Fasciola species have relied on morphological characteristics of adults and eggs. Despite to this, it is usually difficult to accurately discriminate between $F$. hepatica and $F$. gigantica because of the many variations in their morphological characteristics. The differentiation becomes very difficult when dealing with small specimens. At the extremes of this morphological range, some resemble $F$. hepatica, whereas others resemble $F$. gigantica, with intermediate forms also occurring and involving phenomena such as abnormal gametogenesis, diploidy, triploidy and mixoploidy, parthenogenesis, and hybridization events between different genotypes (Mas-Coma \& Bargues, 1997; Marcilla et al., 2002). The two species can also be discriminated by DNA sequences of nuclear ribosomal internal transcribed spacer 1 (ITS-1), ITS-2, and 28S rRNA genes (Adlard et al., 1993; Marcilla et al., 2002; Itagaki \& Tsutsumi, 1998; Itagaki et al., 2005) and of mitochondrial NDI and CO1 genes (Itagaki et al., 2005). There exists no detailed published information on the genotyping and differantiation of $F$. hepatica and/or $F$. gigantica Turkish isolates. Thus, a rapid and simple test for the differentiation of the two 
Fasciola species is needed. The usefulness of molecular genetic techniques based on nuclear and mitochondrial DNA was emphasized while addressing problems of identification, characterization, and phylogeny of parasites. In the present study, PCR-restriction fragment length polymorphism (PCR-RFLP) patterns were analyzed for mitochondrial $\mathrm{CO} 1$ gene after digestion with two restriction enzymes (AluI and RsaI). In addition, nucleotide sequences of the mitochondrial $\mathrm{CO} 1$ gene were determined for $F$. hepatica and $F$. gigantica cattle isolates from Turkey to evaluate the phylogenetic relationships among them.

\section{Materials and methods}

\section{Parasite materials}

Adults of $F$. hepatica and F. gigantica were obtained from livers of naturally infected cattle taken from local abattoirs in Erzurum and Elazig provinces of Turkey, respectively. In a previous study (Balkaya \& Simsek, 2010), a total of 2088 cattle were inspected for bile ducts of liver after slaughter in a local abattoir in Erzurum province and 439 $(21 \%)$ were found to be infected with $F$. hepatica. 15 adult flukes belonged to different hosts were used for DNA isolation. The $F$. gigantica isolate was obtained during the routine inspection of slaughtered cattle in a local abattoir of Elazig province. More than 80 flukes detected in the bile ducts and one of them was used for DNA isolation. Flukes washed extensively in PBS $(\mathrm{pH} 7.2)$ and subsequently fixed in $70 \%$ ethanol and stored at $-20{ }^{\circ} \mathrm{C}$ until used for DNA isolation.

The morphological differantiation of $F$. hepatica and $F$. gigantica were performed according to lineal biometric characters such as body length (BL), maximum body width (BW) and body perimeter (BP).

\section{DNA isolation and amplification}

Total genomic DNA (gDNA) was extracted from the apical zone of adult flukes using standard procedure (Sambrook et al., 1989). Prior to DNA isolation, ethanol-fixed worm were cut from apical zone and washed 5 times with PBS. For the genomic DNA isolation, we used a com-mercially available DNA extraction kit (Promega, Wizard Genomic DNA Purification Kit) following additional proteinase-K $(2 \mathrm{mg} / \mathrm{ml})$ digestion in $56{ }^{\circ} \mathrm{C}$ for overnight. DNA concentration determined by spectrophotometer (NanoDrop-ND1000) and the sample stored at $-20{ }^{\circ} \mathrm{C}$ until use. Fragments of the mitochondrial $\mathrm{CO} 1$ gene were PCR-amplified as reported by Bowles et al. (1992) using the JB3/ JB4.5 primers $\left(5^{\prime}\right.$-TTTTTTGGGCATCCTGAGGTTT AT3'/5' TAAAGAAAGAACATAATGAAAATG3'). PCR amplification was performed in $50 \mu \mathrm{l}$ volumes containing DNA (100 ng), $250 \mu \mathrm{M}$ of each dNTP, $2.5 \mathrm{mM}$ of $\mathrm{MgCl}_{2}$, 20 pmol of each primers, $5 \mu 1$ 10X PCR buffer and $1.25 \mathrm{U}$ TaqDNA polymerase (MBI, Fermentas, Lithu-ania). The PCR conditions were: $5 \mathrm{~min}$ at $95{ }^{\circ} \mathrm{C}$ (initial denaturation), 35 cycles of $50 \mathrm{sec}$ at $94{ }^{\circ} \mathrm{C}, 50 \mathrm{sec}$ at $53{ }^{\circ} \mathrm{C}$ and $50 \mathrm{sec}$ at $72{ }^{\circ} \mathrm{C}$ and finally $10 \mathrm{~min}$ at $72{ }^{\circ} \mathrm{C}$ (final extension). The PCR products were separated on agarose gel $(1.5 \%)$ and stained with ethidium bromide. Then the purified Fasciola mt-CO1 PCR products $(5 \mu \mathrm{l})$ were digested directly with 5 units $(1 \mu \mathrm{l})$ of restriction enzymes AluI and RsaI (Bioron, Ludwigshafen, Germany) in $20 \mu \mathrm{l}$ for $2 \mathrm{~h}$ at $37^{\circ} \mathrm{C}$. Restriction fragments were separated on $3 \%$ agarose gel, stained with ethidium bromide and photographed upon transillumination. The restriction fragments were separated on $3 \%$ agarose gels, stained with ethidium bromide and photographed. These restriction enzymes were chosen the results of restriction map of sequence. Lastly, the $\mathrm{CO} 1$ sequence was automatically obtained using a 377 ABI PRISM system (Applied Biosystems). Nucleotide sequence analysis was undertaken by BLAST algorithms and databases from the National Center for Biotechnology.

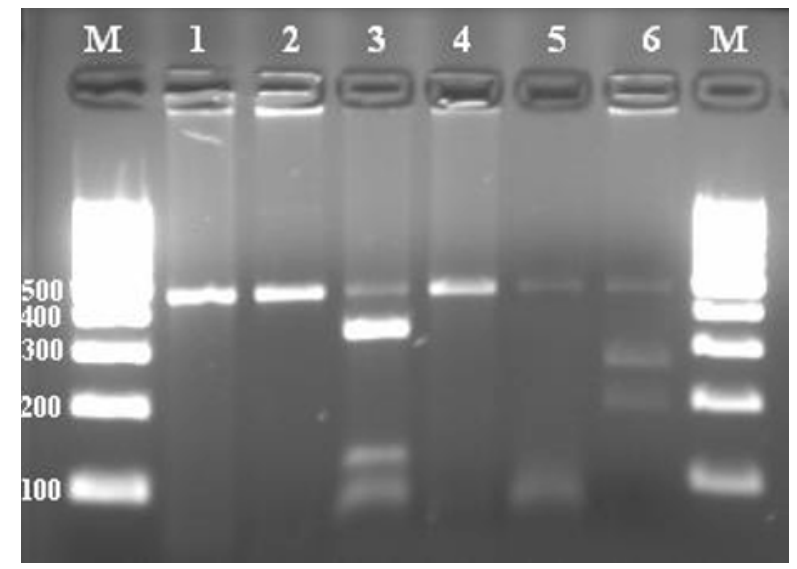

Figure 1. PCR and PCR-RFLP patterns of mitochondrial (mt) CO1 gene of the analyzed isolates. M: DNA marker (100 bp). mt-CO1 of the $F$. hepatica (1) and $F$. gigantica (2). PCR-RFLP patterns obtained from $3 \%$ agarose gel electrophoresis of $F$.hepatica after restriction enzyme digestion with $A l u \mathrm{I}$ (3), RsaI (4). PCR-RFLP patterns of F.gigantica digestion with AluI (5), RsaI (6).

\section{Results and discussion}

The mean morphological characteristics for $F$. hepatica were $19.1 \mathrm{~mm}, 10.4 \mathrm{~mm}$ and $53.2 \mathrm{~mm}$ for BL, BW and BP, respectively. However, these rates for $F$. gigantica were 43.6 mm, $9.7 \mathrm{~mm}$ and $93.8 \mathrm{~mm}$ for BL, BW and BP.

The CO1-PCR with the JB3 and JB4.5 primers yielded of $446 \mathrm{bp}$ amplification products with all samples analysed (Figure 1). In total 16 of $F$. hepatica and 1 of $F$. gigantica isolates were examined by PCR-RFLP analysis of the CO1 region of mt-DNA using two restriction endonucleases (AluI and RsaI) and the RFLP patterns of cattle isolates were presented in Figure 1. The different band patterns generated after digestion and used to differentiate between the two species. After the digestion of the PCR product with the restriction enzyme AluI, the RFLP profile obtained from $F$. hepatica revealed two fragments of approximately 330 and $110 \mathrm{bp}$, whereas $F$. gigantica was not cut (Figure 1). The RsaI digestion generated two fragments of approximately $190 \mathrm{bp}$ and $280 \mathrm{bp}$ from $F$. gigantica, whereas it did not cut the PCR product from $F$. hepatica (Figure 1). The corresponding sequences of $F$. hepatica and $F$. gigantica have been deposited in the 
GenBank $^{\mathrm{TM}}$ databases under the accesion numbers were GQ121276 and GQ121277, respectively. The alignment of these sequences with published sequence results (GQ231549 and GQ231548) for F. hepatica is presented in Figure 2 and for $F$. gigantica (AJ628033 and AJ628022) is shown in Figure 3. According to the alignment results, there was $100 \%$ identity for $F$. hepatica isolate. While this identity rate was $98 \%$ for $F$. gigantica isolate.

Sheep and cattle are heavily infected with liver flukes in Turkey with prevalence of up to $60 \%$ by ELISA (Simsek et al., 2007) and $22.1 \%(303 / 1370)$ by postmortem inspection (unpublished data). Toparlak et al. (1989), examined 495 cattle livers and found as $50.3 \%$ with $F$. hepatica and $1.8 \%$ with $F$. gigantica in east of Turkey. Human infection has been documented in Turkey as $1.8 \%$ in Van province (Yilmaz \& Godekmerdan, 2004) by stool examination and $3.01 \%$ in Antalya (Turhan et al., 2006) and between 0.9 and $6.1 \%$ by serology in Isparta provinces (Demirci et al., 2003), mediterranean region of Turkey. However, there were no detailed published information as to whether both $F$. hepatica and $F$. gigantica occur in human in Turkey and their molecular differentiation. Erensoy et al. (2009), to determine the phylogenetic location of $F$. hepatica of Turkey origin based on ITS-2 rDNA molecular data, adult $F$. hepatica trematodes collected from the liver naturally infected sheep from different geographical locations in Turkey and ITS-2 rDNA sequenced, and compared with published sequences. They found that, primary sequence analysis revealed a close relationship between the query sequence (from Turkey) isolates of $F$. hepatica from China, France, Spain, Australia and isolates of Fasciola sp. from China. Different molecular techniques have been used for the characterization of liver fukes. Concerning the mitochondrial DNA, part of the mt-DNA of $F$. hepatica

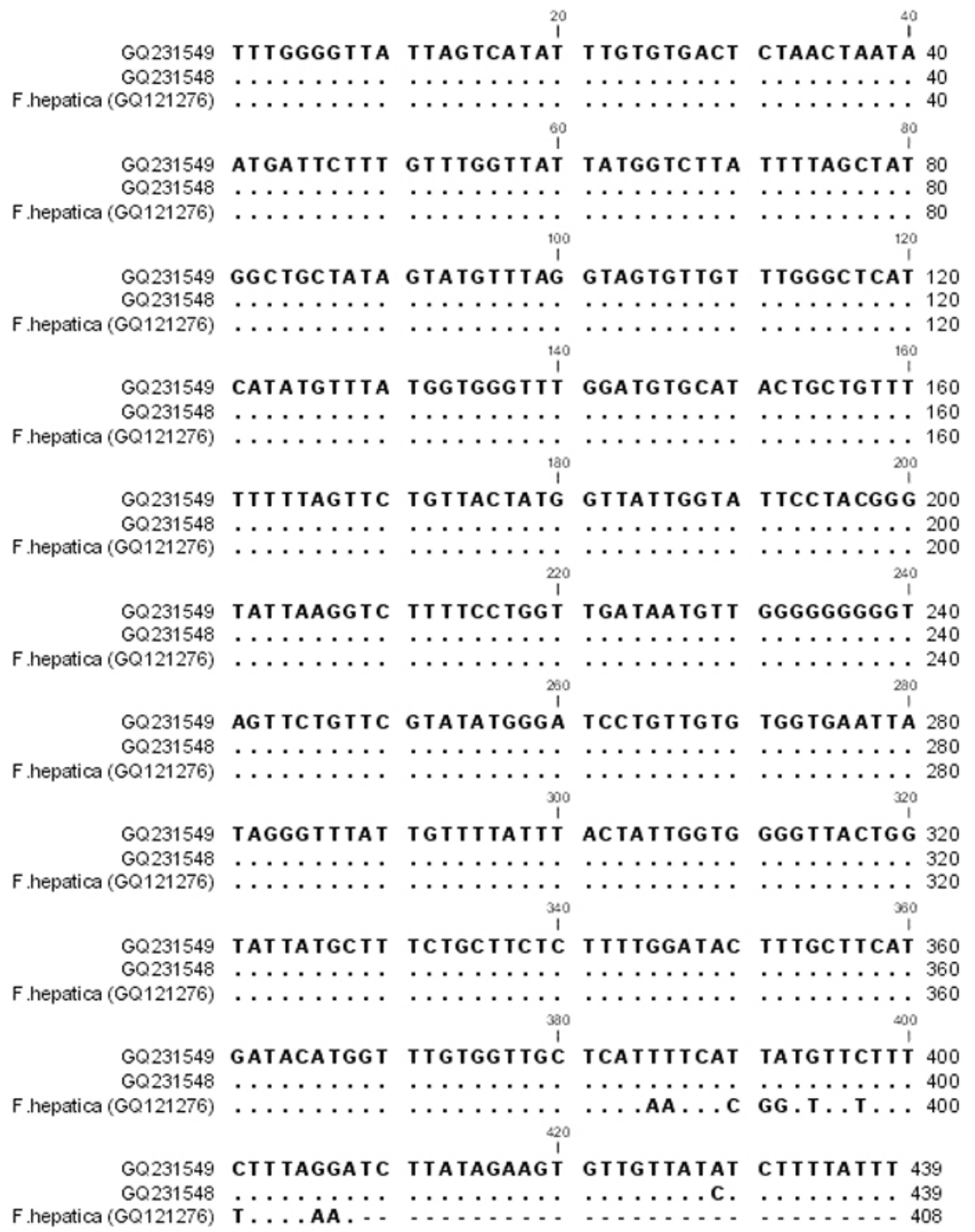

Figure 2. Nucleotide sequences of a fragment (446 bp) of mitochondrial cytochrome $c$ oxidase subunite 1 (CO1) for 2 isolates of Fasciola hepatica analyzed in the study aligned with the published (GenBank TM/EBI Data Bank Accession No. GQ121276) CO1 sequence of the F. hepatica as a reference. A dot indicates a nucleotide that is conserved relative to the published sequence. 


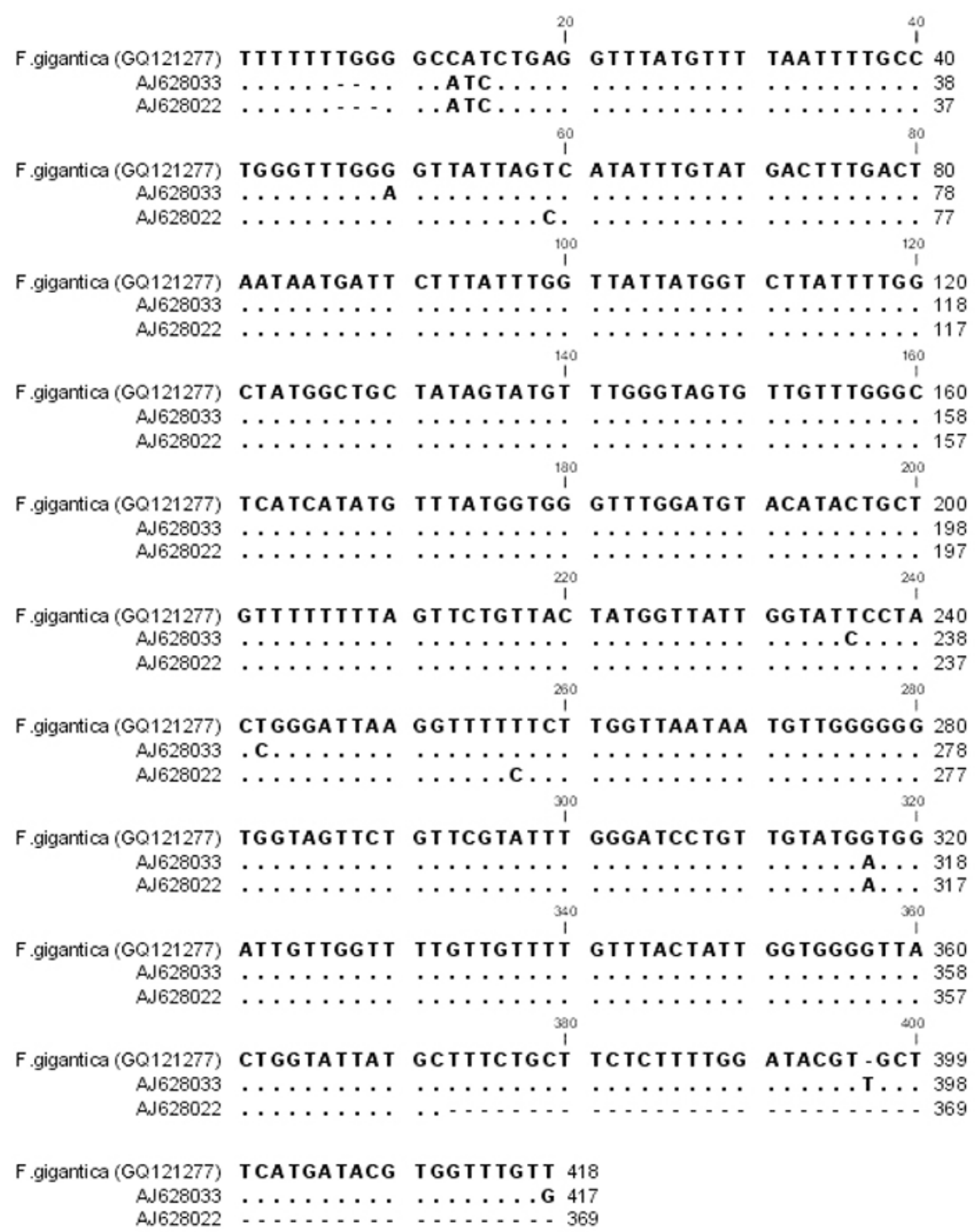

Figure 3. Nucleotide sequences of a fragment (446 bp) of mitochondrial cytochrome $c$ oxidase subunite 1 (CO1) for 2 isolates of Fasciola gigantica analyzed in the study aligned with the published (GenBank TM/EBI Data Bank Accession No. GQ121277) CO1 sequence of the $F$. gigantica as a reference. A dot indicates a nucleotide that is conserved relative to the published sequence.

was sequenced and showed length heterogeneity, suggesting length differences among individual mitochondrial genomes (Marcilla et al., 2002).

In the present study, the mt-DNA CO1 gene digestion patterns differed markedly between $F$. hepatica and $F$. gigantica. Given the variation observed within the short region of the $\mathrm{CO} 1$ gene sequenced, there are likely to be considerable differences in RFLP patterns. Restriction fragment length polymorphism patterns were analysed for the whole mt-DNA of $F$. hepatica from Australia, F. gigantica from Malaysia and Fasciola sp. from Japan after digestion with HinfI, MspI and RsaI endonucleases (Hashimoto et al., 1997). The mt-DNA digestion patterns differed markedly between the three fasciolids. For each enzyme there were some bands specific for each geographical isolate, the Japanese Fasciola sp. sharing more bands with $F$. gigantica than with $F$. hepatica. However, given the variation observed within the short region of the
CO1 gene sequenced, there are likely to be considerable differences in RFLP patterns even between quite closely related forms. Moreover, intraspecific variation was found at one nucleotide site between different specimens from the same $F$. gigantica population from Malaysia (Hashimoto et al., 1997). Concerning ribosomal DNA, restriction endonuclease maps of the rRNA genes were distinct for $F$. hepatica and F. gigantica, Japanese Fasciola sp. being identical in restriction map to $F$. gigantica. No intraspecific variations in the maps of $F$. hepatica or of $F$. gigantica were detected, but length heterogeneity was noted in the intergenic spacer, even within individual worms (Blair \& McManus, 1989). The ITS-2 of the rDNA has been used several times for liver flukes differentiation (Itagaki \& Tsutsumi, 1998; Andrews, 1999; Huang et al., 2004). One nucleotide difference in a 263 bp long ITS-2 fragment between the $F$. hepatica population from Mexico and those from Australia, Hungary and New Zealand, and 
no difference in the $213 \mathrm{bp}$ long ITS-2 fragment compared between $F$. gigantica from Indonesia and Malaysia were found (Andrews, 1999).

The nucleotide sequences were obtained for mt-CO1 gene were obtained of adult $F$. hepatica and $F$. gigantica and were compared with sequences of other species in GenBank. The BLAST hit results shown that our query mtCO1 sequences were much more similar to the sequences of various geographical isolates of $F$. hepatica and $F$. gigantica.

In this study, we present a new approach of molecular differentiation of fasciolid flukes by using distinct endonucleases from previous work in PCR-RFLP of mitochondrial CO1 gene region. The nucleotide variation in the CO1 sequences of the cattle isolates of $F$. hepatica and $F$. gigantica resulted in difference in restriction sites for endonucleases AluI and RsaI. Consistent with CO1 sequence data, $F$. hepatica and $F$. gigantica could be differentiated from one another unequivocally using either AluI or RsaI based on their unique restriction banding patterns.

The PCR-RFLP method described here can be used for the proper identification of Fasciola species. Moreover, this method may be very useful for epidemiological surveys on both human and livestock fascioliosis in high endemic regions.

\section{References}

Adlard, R. D., Barker, S. C., Blair, D., CribB, T. H. (1993): Comparison of the second internal transcribed spacer (ribososmal DNA) from populations and species of Fasciolidae (Digena). Int. J. Parasit., 23: 423 - 425

ANDREWS, S. J. (1999): The life cycle of Fasciola hepatica. In: DALTON, J. P. (Ed.) Fasciolosis. CAB International Publishing, Oxon, UK, 1 - 29

Balkaya, I., SimseK, S. (2010). Prevalence and economic importance of hydatidosis and fasciolosis in slaughtered cattle in Erzurum province of Turkey. Kafkas Univ. Vet. Fak. Derg. 16: 793 - 797

BlaIR, D., MCMANUS, D. P. (1989): Restriction enzyme mapping of ribosomal DNA can distinguish between fasciolid (liver fluke) species. Mol. Biochem. Parasitol. 36: $201-$ 208

Bowles, J., Blair, D., McManus, D. P. (1992): Genetic variants within the genus Echinococcus identified by mitochondrial DNA sequencing. Mol. Biochem. Parasitol. 54: $165-174$

Demirci, M., Korkmaz, M., KayA, S., Kuman, A. (2003): Fascioliasis in eosinophilic patients in the Isparta region of Turkey. Infection, 31: $15-18$
EREnSOY, A., KuK, S., Ozden, M. (2009): Genetic identification of Fasciola hepatica by ITS-2 sequence of nuclear ribosomal DNA in Turkey. Parasitol. Res. 105: 407 - 412 HAShimoto, K., Watanobe, T., LiU, C. X., Init, I., Blair, D., Ohnishi, S., Agatsuma, T. (1997): Mitochondrial DNA and nuclear DNA indicate that the Japanese Fasciola species is F. gigantica. Parasitol. Res. 83: $220-225$

HuANG, W. Y., He, B., WANG, C. R., ZHU, X. Q. (2004): Characterisation of Fasciola species from Mainland China by ITS-2 ribosomal DNA sequence. Vet. Parasitol. 120: 75 $-83$

ItAgaki, T., Tsutsumi, K. (1998): Triploid form of Fasciola in Japan: genetic relationships between Fasciola hepatica and Fasciola gigantica determined by ITS-2 sequence of nuclear rDNA. Int. J. Parasitol. 28: 777 - 781 Itagaki, T., Kikawa, M., Sakaguchi, K., Shimo, J., Terasaki, K., Shibahara, T., Fukuda, K. (2005): Genetic characterization of parthenogenic Fasciola sp. in Japan on the basis of the sequences of ribosomal and mitochondrial DNA. Parasitology, 131: $679-685$

Marcilla, A., Bargues, M. D., MAs-ComA, S. (2002): A PCR-RFLP assay for the distinction between Fasciola hepatica and Fasciola gigantica. Mol. Cel. Prob. 16: 327 333

Mas-Coma, S., Bargues, M. D. (1997): Human liver flukes: a review. Res. Rev. Parasitol. 57: 145 - 218

McManus, D. P., Bowles, J. (1996). Molecular genetic approaches to parasite identification: their value in diagnostic parasitology and systematics. Int. J. Parasitol. 26: $687-704$

SAMBrooK, J., Fritsch, E. F., Maniatis, T. (1989): Detection and Analysis of Proteins Expressed from Cloned Genes. Molecular Cloning. A Laboratory Manual. Cold Spring, Harbor Laboratory press. New York, USA.

SimseK, S., Risvanli, A., UtuK, A. E., YuKSEl, M., SAAT, N., Koroglu, E. (2007): Evaluation of relationship between repeat breeding and Fasciola hepatica and hydatid cyst infections in cows in Elazig district of eastern Turkey. Res. Vet. Sci. 83: $102-104$

TOPARlaK, M., TASCI, S., Gul, Y. (1989): Liver fluke infections in cattle slaughtered in Van abattoir. Vet. J. Ankara Univ. 36: 419 - 423

Turhan, O., Korkmaz, M., SABA, R., KabAaAlioglu, A., InAN, D., MAMIKOGLU, L. (2006). Seroepidemiology of fascioliasis in the Antalya region and uselessness of eosinophil count as a surrogate marker and portable ultrasonography for epidemiological surveillance. Infez Med. 14: $208-212$

YilmaZ, H., GodeKMERdAN, A. (2004). Human fasciolosis in Van province, Turkey. Acta Trop. 92: $161-162$ 